\title{
The Impact of Palliative Care Team Consultation on Quality of Life of Patients with Advanced Cancer in Dutch Hospitals: An Observational Study
}

\author{
Arianne Brinkman-Stoppelenburg ${ }^{a} \quad$ Yvonne Vergouwe $^{a} \quad$ Monique Booms $^{b}$ \\ Mathijs P. Hendriks ${ }^{c}$ Liesbeth A. Peters ${ }^{d}$ Patricia Quarles van Ufford-Mannesse ${ }^{e}$ \\ Frederiek Terheggen $^{f}$ Sylvia Verhage ${ }^{g}$ Maurice J.D.L. van der Vorst ${ }^{\text {h, }}$ i \\ Ingrid Willemen ${ }^{j}$ Suzanne Polinder ${ }^{a} \quad$ Agnes van der Heide ${ }^{a}$ \\ aDepartment of Public Health, Erasmus MC, University Medical Center Rotterdam, Rotterdam, The Netherlands; \\ ${ }^{b}$ Department of Medical Oncology, Erasmus MC Cancer Institute, Rotterdam, The Netherlands; ' Department of Internal \\ Medicine, Northwest Clinics, Alkmaar, The Netherlands; ${ }^{\mathrm{d}}$ Department of Pulmonary Diseases, Northwest Clinics, Den \\ Helder, The Netherlands; ${ }^{e}$ Department of Medical Oncology, Haga Hospital, The Hague, The Netherlands; ${ }^{f}$ Department \\ of Internal Medicine, Bravis Hospital, Bergen op Zoom, The Netherlands; ${ }^{9}$ Breast Center, Jeroen Bosch Hospital,

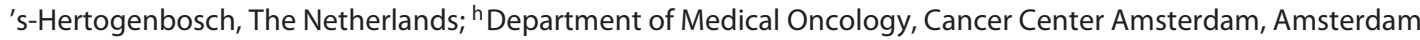 \\ UMC, Amsterdam, The Netherlands; 'Department of Internal Medicine, Rijnstate Hospital, Arnhem, The Netherlands; \\ jDepartment of Internal Medicine, Elisabeth-Tweesteden Hospital, Tilburg, The Netherlands
}

\section{Keywords}

Palliative care $\cdot$ Palliative medicine $\cdot$ Referral and consultation · Quality of life · Hospitals · Observational study

\footnotetext{
Abstract

Introduction: Experimental studies have shown that palliative care team (PCT) involvement can improve quality of life (QoL) and symptom burden of patients with advanced cancer. It is unclear to what extent this effect is sustained in daily practice of hospital care. Objective: This observational study aims to investigate the effect of PCT consultation on QoL and symptom burden of hospitalized patients with advanced cancer in daily practice. Methods: After admission to 1 of 9 participating hospitals, patients with advanced cancer for whom the attending physician answered "no" to the Surprise Question were invited to complete a questionnaire, including the EORTC QLQ-C15-PAL, at 6 points in time, until 3 months after admission. Outcomes were compared between patients who received PCT consultation and patients who did not, taking into account differences in baseline characteristics. Results: A total of 164 patients consented to par-
}

karger@karger.com www.karger.com/ort

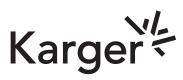

(C) 2020 The Author(s)

Published by S. Karger AG, Basel

This is an Open Access article licensed under the Creative Commons Attribution-NonCommicial-4.0 International License (CC BY-NC) (http://www.karger.com/Services/OpenAccessLicense), applicable to mercial purposes requires written permission. ticipate, of whom 32 received PCT consultation. Of these patients, 108 were able to complete a questionnaire at day 14, of whom 19 after receiving PCT consultation. After adjusting for baseline differences, EORTC QLQ-C15-PAL scores for pain, appetite, and emotional functioning at day 14 were more favorable for patients who received a PCT consultation. Conclusion: PCT consultation decreased patients' symptom burden and tends to have a positive effect on QoL of hospitalized patients with advanced cancer, even if the PCT is consulted late in the patient's disease trajectory.

\section{(c) 2020 The Author(s)}

Published by S. Karger AG, Basel

\section{Introduction}

The evidence that specialist palliative care has positive effects on the quality of life (QoL) and symptom burden of patients with advanced cancer has increased over the past years [1-5]. In a meta-analysis of randomized controlled trials, Kavalieratos et al. [3] concluded that palliative care can lead to significant improvements in patients' QoL and symptom burden after 1-3 months of follow-up. High-quality studies that support this conclusion were 
mainly performed in the ambulatory setting or among patients residing at home, with palliative care involvement occurring relatively early in patients' disease trajectory, for example, shortly after the diagnosis of metastatic cancer [6-8]. In another meta-analysis, Gaertner et al. [4] found that multidisciplinary specialist palliative care had a small effect on QoL in patients with advanced illness. They suggest that specialist palliative care might have the most substantial effects for patients with cancer in an earlier stage of their disease. In an older review from 2002, which specifically focused on the effect of hospitalbased palliative care teams (PCTs), it was concluded that such teams offer some benefits, although there was a lack of high-quality studies in this area [9].

In the Netherlands, palliative care is an integral part of regular healthcare and not a distinct medical specialty. In case of complex problems, specialist palliative care can be provided by regional or hospital PCTs. The number of hospital PCTs has risen substantially over the past 5 years [10]. Most hospital PCTs can be consulted by medical specialists and nurses working in the hospital. Upon their involvement, PCTs typically provide a detailed holistic assessment of patients' symptoms and their physical, emotional, social, and spiritual problems, prioritize these and propose an advice on how to address them [11]. The extent to which PCTs provide care themselves or only advise the primary caregivers varies. Further, there are substantial differences between teams regarding the disciplines represented in the teams, the procedures followed, and the frequency of consultations [12].

In 2015, PCTs provided consultations in $0.6 \%$ of all hospital admissions [12]. This percentage is low when compared to other countries, for example, the United States, were a percentage of $4.4 \%$ was found [13]. The Dutch Federation of Oncological Societies has set standards for PCTs in hospitals, but these do not include standards regarding the timing of consultation [14], despite the fact the evidence indicates that specialist palliative care might have a more substantial effect in patients with cancer in an earlier stage of their disease [4].

Evidence on the effects of PCT consultation in hospitals mainly comes from experimental studies in outpatient clinics. It is unclear to what extent this effect is sustained in the daily practice of hospital inpatient care. We performed a longitudinal, observational study to investigate the association between PCT consultation and survival, QoL, and symptom burden of hospitalized patients with incurable cancer in the Netherlands.

\section{Materials and Methods}

The study protocol has been described in detail elsewhere [11] We provide a summary here.

\section{Patients and Setting}

Patients were included after having been admitted to a medical oncology ward in 1 of 9 participating hospitals between February 2013 and March 2015. Seven hospitals had a PCT. Two hospitals without a PCT were included to ensure sufficient comparable patients for whom no PCT was involved but who were in principle eligible for the study and would be recruited.

Eligible were patients with cancer aged 18 years or older for whom the attending physician answered "no" to the Surprise Question: "Would you be surprised if this patient would die in the next year?" $[15,16]$ and who were expected to stay in the hospital for at least 3 days. After identification by the attending physician, patients received an information letter and were asked to participate by an attending nurse. Patients who consented were included within 3 days after admission. All patients were followed for 3 months after inclusion, regardless of where they stayed.

\section{Questionnaires}

Patients filled in questionnaires at days $1,4,14,30,60$, and 90 after inclusion. The attending physician was asked to fill in a questionnaire about the patient's diagnosis, WHO performance status, comorbidity, treatment status, and life expectancy. In the patient questionnaire, QoL was assessed with the EORTC QLQ-C15 PAL [17].

This is an abbreviated version of the EORTC QLQ-C30 that consists of 14 questions on symptoms and functioning that can be answered on a numerical scale from 1 (not at all) to 4 (very much), and one question on global QoL, which is rated from 1 (very poor) to 7 (excellent) [18]. The main outcome for our study was QoL as assessed by the EORTC-QLQ-C15 PAL at day 14 after inclusion.

We also measured QoL with the Palliative Outcome Scale (POS) [19] and the EuroQol-5D [20, 21]. The POS is a questionnaire for patients with advanced cancer that covers physical symptoms and QoL, as well as emotional, social, psychological, and spiritual aspects. The EuroQol 5 dimensions questionnaire (EQ-5D) assesses mobility, self-care, usual activities, pain/discomfort, and anxiety/depression on a three-level scale (no problems, some problems, and extreme problems) [22].

\section{PCT Consultation}

All PCTs in our study adhered to the standards of the Dutch Federation of Oncological Societies [14]. Standards are for instance that PCTs should include at least 2 medical specialists and a nurse, who should meet at least weekly. If needed, members of the PCT should also have the possibility to consult other disciplines with expertise in palliative care. Upon their involvement in patients' care, PCTs typically provide a detailed holistic assessment of patients' symptoms and their physical, emotional, social, and spiritual problems, prioritize these and propose an advice on how to address them. Although all PCTs adhered to the SONCOS standards, consultation in itself was not a standardized intervention, and PCTs differed regarding, for example, disciplines represented in the teams and working procedures. An overview of characteristics of PCTs that participated in this study is provided in the online supplementary appendix 1 (see www.karger.com/doi/10.1159/000508312).

\section{Data Analysis}

We analyzed the association of PCT consultation with EORTCQLQ-C15 PAL QoL scores in a linear regression analysis, while adjusting for baseline QoL scores and baseline differences in patient characteristics. Baseline characteristics that were both associated with the receipt of PCT consultation $(p \leq 0.3)$ and with QoL on day $14(p \leq 0.3)$ were considered potential confounders and were included in the analysis. Since the residuals in the linear regression were not normally distributed, we used bootstrapping to calculate $95 \%$ confidence intervals (CIs). 

Table 1. Baseline characteristics of patients with and without PCT consultation $(n=164)$

\begin{tabular}{|c|c|c|c|}
\hline & $\begin{array}{l}\text { Patients without } \\
\text { PCT consultation } \\
(n=132)\end{array}$ & $\begin{array}{l}\text { Patients with } \\
\text { PCT consultation } \\
(n=32)\end{array}$ & $p$ value \\
\hline Age, years & $68(60-74)$ & $69(56-76)$ & $0.98^{\mathrm{a}}$ \\
\hline Female gender & $66(50)$ & $18(56)$ & $0.53^{\mathrm{b}}$ \\
\hline \multicolumn{4}{|l|}{ Type of cancer } \\
\hline Gastrointestinal cancer & $56(43)$ & $14(45)$ & $0.70^{\mathrm{b}}$ \\
\hline Urogenital or gynaecological cancer & $20(15)$ & $7(23)$ & \\
\hline Breast cancer & $19(15)$ & $3(10)$ & \\
\hline Lung cancer & $19(15)$ & $5(16)$ & \\
\hline Other & $17(13)$ & $2(7)$ & \\
\hline Comorbidities & & & $0.85^{\mathrm{b}}$ \\
\hline No comorbidities & $52(39)$ & $11(34)$ & \\
\hline 1 comorbidity & $44(33)$ & $11(34)$ & \\
\hline$>1$ comorbidities & $36(27)$ & $10(31)$ & \\
\hline Time since diagnosis, years & $2(1-10)$ & $3(0-13)$ & $0.62^{\mathrm{a}}$ \\
\hline \multicolumn{3}{|l|}{ Estimated life expectancy, months } & $0.08^{\mathrm{b}}$ \\
\hline $6-12$ & $43(33)$ & $5(16)$ & \\
\hline $3-6$ & $42(32)$ & $9(28)$ & \\
\hline $1-3$ & $37(28)$ & $12(38)$ & \\
\hline$<1$ & $10(8)$ & $6(19)$ & \\
\hline \multicolumn{3}{|l|}{ WHO performance status } & $0.03^{\mathrm{b}}$ \\
\hline Able to carry out all normal activity without restrictions & $11(8)$ & $1(3)$ & \\
\hline Restricted in physically strenuous activity but ambulatory and able to carry out light work & $45(34)$ & $6(19)$ & \\
\hline \multicolumn{4}{|l|}{ Ambulatory and capable of all self-care but unable to carry out any work; up and $>50 \%$} \\
\hline of waking hours & $37(28)$ & $6(19)$ & \\
\hline Capable of only limited self-care; confined to bed or chair $>50 \%$ of waking hours & $33(25)$ & $15(47)$ & \\
\hline Completely disabled; cannot carry out any self-care; totally confined to bed or chair & $6(5)$ & $4(13)$ & \\
\hline Number of hospital admissions due to current disease & $2(1-4)$ & $2(1-2)$ & $0.11^{\mathrm{a}}$ \\
\hline \multicolumn{3}{|l|}{ Current hospital admission was } & $0.31^{\mathrm{b}}$ \\
\hline Planned & $22(17)$ & $3(10)$ & \\
\hline Unplanned & $106(83)$ & $28(90)$ & \\
\hline \multicolumn{3}{|l|}{ Treatment status at the time of admission: } & $<0.01^{\mathrm{b}}$ \\
\hline Patient received anti-tumor therapy & $62(47)$ & $9(28)$ & \\
\hline No options for anti-tumor therapy left & $41(31)$ & $21(66)$ & \\
\hline Other & $29(22)$ & $2(6)$ & \\
\hline
\end{tabular}

Values are presented as median (interquartile range) or $n(\%) .{ }^{a}$ Mann-Whitney $\mathrm{U}$ test. ${ }^{\mathrm{b}} \chi^{2}$ test.

\section{Results}

\section{Baseline Characteristics}

Between February 2013 and March 2015, a total of 164 patients were included in the study, of whom 32 received PCT consultation. Hospitals with a PCT recruited between 2 and 6 patients who received PCT consultation for the study. Among patients with PCT involvement, 56\% were female, compared to $50 \%$ among patients without PCT involvement; the median age was 69 and 68 years, respectively. In both groups, gastrointestinal cancer was the most common diagnosis (Table 1).

There were significant differences in patients' health status between both groups. Patients' life expectancy as estimated by the physician was more limited for patients with PCT involvement compared to patients without PCT involvement; $57 \%$ of the patients with PCT in- volvement had an estimated life expectancy of $<3$ months, compared to $36 \%$ of the patients without PCT involvement (Table 1). WHO performance status was also worse for patients with PCT involvement: $60 \%$ of the patients with PCT involvement were only capable of limited self-care or completely disabled, compared to $30 \%$ of the patients without PCT involvement. Patients with PCT involvement more often had a non-planned hospitalization (90 vs. 83\%). Furthermore, for patients with PCT involvement, the physician more often indicated that there were no more options for anti-tumor therapy (66 vs. $31 \%$ ). Baseline EORTC QoL scores of patients with PCT involvement were worse compared to scores of patients without PCT involvement (38.5 vs. 50.9), as were scores for physical functioning, fatigue, nausea and vomiting, pain, constipation, and appetite loss (Table 2). 
Table 2. QoL scores at baseline of patients with and without PCT consultation $(n=164)$

\begin{tabular}{|c|c|c|c|c|}
\hline & $\begin{array}{l}\text { Patients } \\
\text { without PCT } \\
\text { consultation, } n\end{array}$ & Score & $\begin{array}{l}\text { Patients } \\
\text { with PCT } \\
\text { consultation, } n\end{array}$ & Score \\
\hline \multicolumn{5}{|l|}{ Eortc QLQ C15 Pal } \\
\hline Physical functioning* & 125 & 40.8 & 28 & 32.4 \\
\hline Emotional functioning* & 124 & 71.1 & 28 & 71.4 \\
\hline Fatigue* & 124 & 63.1 & 30 & 78.5 \\
\hline Nausea and vomiting* & 125 & 25.3 & 30 & 44.4 \\
\hline Pain* & 126 & 48.0 & 30 & 67.8 \\
\hline Dyspnea* & 126 & 34.4 & 30 & 33.3 \\
\hline Insomnia* & 126 & 41.0 & 30 & 41.1 \\
\hline Appetite loss* & 126 & 46.8 & 30 & 57.8 \\
\hline Constipation* & 123 & 29.0 & 30 & 50.0 \\
\hline Global health status* & 127 & 50.9 & 29 & 38.5 \\
\hline \multicolumn{5}{|l|}{ EQ-5D** } \\
\hline Dutch EQ-5D Summary Score & 121 & 0.54 & 30 & 0.45 \\
\hline \multicolumn{5}{|l|}{ POS } \\
\hline Physical $^{* * *}$ & 124 & 3.0 & 28 & 4.2 \\
\hline Psychological*** & 124 & 6.7 & 30 & 8.0 \\
\hline Information ${ }^{* * *}$ & 124 & 1.9 & 29 & 2.2 \\
\hline Total score $\dagger$ & 116 & 11.6 & 27 & 14.3 \\
\hline
\end{tabular}

* EORTC QLQ C15 PAL: range 0-100. For physical functioning, emotional functioning, and global health status higher score implies better status. For individual symptoms, higher score implies a severe burden of symptoms (worse status). ${ }^{* *}$ EQ-5D: range -0.33 to -1 , a higher score implies better QoL. ${ }^{* * *}$ Palliative Outcome Scale (POS) subscales: POS physical scale 0-12, POS psychological scale 0-20, POS information scale 0-12; a higher score implies worse outcome. $\dagger$ POS total scale 0-40; a higher score implies worse outcome.

Table 3. Follow-up of patients with and without PCT consultation $(n=164)$

\begin{tabular}{llll}
\hline & $\begin{array}{l}\text { Patients without } \\
\text { PCT consultation } \\
(n=132)\end{array}$ & $\begin{array}{l}\text { Patients with } \\
\text { PCT consultation } \\
(n=32)\end{array}$ & $p$ value \\
\hline $\begin{array}{l}\text { Duration of hospital admission, days } \\
\text { Discharge destination }\end{array}$ & $8.0(5-13)$ & $8.5(6-18)$ & $0.97^{\mathrm{a}}$ \\
$\quad$ Home & $105(81)$ & $21(65)$ & $0.08^{\mathrm{b}}$ \\
$\quad$ Hospice & $16(12)$ & $5(16)$ & $5(16)$ \\
$\quad$ Other & $5(4)$ & $1(3)$ & $0.02^{\mathrm{b}}$ \\
$\quad$ Deceased during hospital admission & $72(55)$ & $53(28-90)$ & $0.03^{\mathrm{a}}$ \\
Patients surviving 3 months of follow-up, $\%$ & $90(47-90)$ & $53(2)$ & \\
Survival after 3 months follow-up & &
\end{tabular}

Values are presented as median (interquartile range) or $n(\%) .{ }^{\mathrm{a}}$ Mann-Whitney $\mathrm{U}$ test. ${ }^{\mathrm{b}} \chi^{2}$ test.

\section{Survival and Follow-Up}

Out of 164 included patients, 108 patients filled in a questionnaire at day 14, of whom 19 patients received PCT consultation. At day 30, 84 patients filled in a questionnaire, of whom 11 were PCT patients. There was not only a difference in estimated life expectancy, but also in actual survival between the 2 groups (Table 3): $69 \%$ of the patients with PCT involvement did not survive 3 months of follow-up, compared to $45 \%$ of the patients without PCT involvement.

\section{Quality of Life}

The analysis of the association between PCT consultation and QoL at day 14 was adjusted for patients' age, sex, baseline scores for QoL, WHO performance status, life expectancy, treatment status, and whether the hospitalization was planned. Patients with PCT consultation had significantly better scores for pain (difference of 17.6 points, $95 \%$ CI -30.6 to -4.6 ), appetite loss (difference of 23.3 points, $95 \%$ CI -43.9 to -4.6 ) and emotional functioning (difference of 10.6 points, 95\% CI $0.0-20.6$ ) as 
Table 4. QoL scores of patients with and without PCT consultation at baseline and 14 days of follow-up $(n=108)$

\begin{tabular}{|c|c|c|c|c|c|}
\hline QoL & & Without PCT & $n$ & With PCT & PCT effect $\beta$ (95\% CI) \\
\hline \multicolumn{6}{|c|}{ EORT C QLQ C15 PAL } \\
\hline \multicolumn{6}{|c|}{ Physical functioning* } \\
\hline Baseline QoL & 83 & 41.8 & 17 & 34.9 & \multirow[t]{2}{*}{$10.96(-0.12$ to 22.89$)$} \\
\hline 14 days QoL & 83 & 37.2 & 17 & 37.3 & \\
\hline \multicolumn{6}{|c|}{ Emotional functioning* } \\
\hline Baseline QoL & 86 & 72.7 & 17 & 69.1 & \multirow[t]{2}{*}{$10.56(0.02$ to 20.55$)$} \\
\hline 14 days QoL & 86 & 74.8 & 17 & 83.3 & \\
\hline \multicolumn{6}{|l|}{ Fatigue* $^{*}$} \\
\hline Baseline QoL & 83 & 60.9 & 19 & 83.0 & \multirow[t]{2}{*}{$-7.01(-18.97$ to 4.91$)$} \\
\hline 14 days QoL & 83 & 57.4 & 19 & 65.5 & \\
\hline \multicolumn{6}{|c|}{ Nausea and vomiting* } \\
\hline Baseline QoL & 85 & 25.7 & 19 & 48.2 & \multirow[t]{2}{*}{$-1.08(-15.93$ to 14.26$)$} \\
\hline 14 days QoL & 85 & 15.8 & 19 & 17.5 & \\
\hline \multicolumn{6}{|l|}{ Pain* } \\
\hline Baseline QoL & 87 & 45.2 & 19 & 68.4 & \multirow[t]{2}{*}{$-17.56(-30.57$ to -4.58$)$} \\
\hline 14 days QoL & 87 & 34.1 & 19 & 30.7 & \\
\hline \multicolumn{6}{|l|}{ Dyspnea* } \\
\hline Baseline QoL & 87 & 33.3 & 18 & 38.9 & \multirow[t]{2}{*}{$4.82(-8.24$ to 21.20$)$} \\
\hline 14 days QoL & 87 & 26.8 & 18 & 35.2 & \\
\hline \multicolumn{6}{|l|}{ Insomnia* } \\
\hline Baseline QoL & 87 & 40.6 & 18 & 42.6 & \multirow[t]{2}{*}{$-9.40(-24.57$ to 5.99$)$} \\
\hline 14 days QoL & 87 & 31.4 & 18 & 22.2 & \\
\hline \multicolumn{6}{|l|}{ Appetite loss* } \\
\hline Baseline QoL & 86 & 48.8 & 18 & 62.9 & \multirow[t]{2}{*}{$-23.30(-43.90$ to -4.68$)$} \\
\hline 14 days QoL & 86 & 44.2 & 18 & 29.6 & \\
\hline \multicolumn{6}{|l|}{ Constipation* } \\
\hline Baseline QoL & 85 & 25.8 & 18 & 57.4 & \multirow[t]{2}{*}{$6.78(-15.18$ to 26.87$)$} \\
\hline 14 days QoL & 85 & 18.8 & 18 & 38.9 & \\
\hline \multicolumn{6}{|c|}{ Global health status* } \\
\hline Baseline QoL & 85 & 51.7 & 16 & 30.2 & \multirow[t]{2}{*}{$12.05(-2.59$ to 25.98$)$} \\
\hline 14 days QoL & 85 & 58.0 & 16 & 60.4 & \\
\hline \multicolumn{6}{|l|}{$E Q-5 D$} \\
\hline EQ-5D** & & & & & \\
\hline Baseline QoL & 79 & 0.55 & 18 & 0.44 & $0.10(-0.12$ to 0.29$)$ \\
\hline 14 days QoL & 79 & 0.54 & 18 & 0.52 & \\
\hline Palliative Outcome & & & & & \\
\hline POS total ${ }^{* *}$ & & & & & \\
\hline Baseline QoL & 77 & 11.80 & 16 & 14.62 & $-2.21(-5.21$ to 0.51$)$ \\
\hline 14 days QoL & 77 & 10.92 & 16 & 10.56 & \\
\hline POS physical** & & & & & \\
\hline Baseline QoL & 85 & 3.09 & 18 & 4.28 & $-0.15(-1.04$ to 0.83$)$ \\
\hline 14 days QoL & 85 & 2.36 & 18 & 2.83 & \\
\hline POS psychological & & & & & \\
\hline Baseline QoL & 84 & 6.69 & 18 & 8.22 & $-0.83(-2.25$ to 0.58$)$ \\
\hline 14 days QoL & 84 & 5.99 & 18 & 6.10 & \\
\hline POS information* & & & & & \\
\hline Baseline QoL & 82 & 1.87 & 18 & 2.39 & $-0.68(-1.98$ to 0.71$)$ \\
\hline 14 days QoL & 82 & 2.32 & 18 & 2.11 & \\
\hline
\end{tabular}

Adjusted for baseline score, age, sex, life expectancy, treatment status, WHO performance status, and type of admission. For all analysis, the group of patients without PCT consultation is the reference group. * EORTC QLQ C15 PAL: range 0-100. For physical functioning, emotional functioning, and global health status higher score implies better status. For individual symptoms, higher score implies a severe burden of symptoms (worse status). ${ }^{* *}$ EQ-5D: range -0.33 to -1 ; a higher score implies better QoL. 

compared to patients without PCT consultation. Patients with PCT consultation also had better scores for physical functioning (difference of 11.0 points, $95 \%$ CI -0.1 to -22.9) and global health status (EORTC QLQ C15 PAL, difference of 12.1 points, $95 \%$ CI -2.6 to 26.0 ). PCT involvement was not associated with QoL as measured by the EQ5D or the (subscales of the) POS (Table 4).

\section{Discussion}

In this observational study, PCT consultation seems to have a beneficial effect on symptoms and tends to have a positive effect on the QoL of hospitalized patients with advanced cancer after 2 weeks of follow-up. Experimental studies mostly found effects after 3 months of follow-up; due to the limited number of included patients and the loss to follow-up, we were not able to assess the effect of PCT involvement beyond 14 days of follow-up.

In this study on real-life clinical practice, it was difficult to include and follow patients: only 32 patients who received PCT consultation participated in our study, and many patients were lost to follow-up. At baseline, patients for whom the PCT was consulted had a higher symptom burden, were more often admitted unplanned, and had a shorter life expectancy compared to patients who did not receive PCT consultation. Consultation seems to occur late in patients' disease trajectory: about two-thirds of the patients with PCT consultation had no options for antitumor therapy left and did not survive 3 months of follow-up. While it seems likely that patients' health status often precluded participation in our study, especially in the PCT group, gatekeeping, which is the phenomenon that physicians protect eligible patients from participation in a study, may also have contributed to the low number of included patients [23]. Furthermore, the high intensity of this study may have contributed to the low recruitment rate. Another issue is that in some hospitals, the PCT was established relatively recently and did not yet have many consultations during the study period. Overall, the referral rates to PCT consultation in Dutch hospitals is low [12].

Due to the high workload of physicians in the participating hospitals and wards, we were not able to collect reliable information on the response rate, which can be considered as a weakness of this study.

Despite the low number of patients, we found significant improvements in patients' scores for pain, appetite loss, and emotional functioning. In their meta-analyses of randomized clinical trials that assessed the effects of specialist palliative care in hospitals, both Kavalieratos et al. [3] and Gaertner et al. [4] reported significant but small improvements in QoL and inconclusive results for symptom burden. An explanation for these small effects may be the approach that is used in many trials, in which specialist palliative care is provided to all patients with a certain diagnosis, even if they did not have explicit palliative care needs. Further, patients in the control groups in these trials could also have received symptom treatment and palliative care from their primary caregivers.

Compared to the experimental studies that were included in both meta-analyses, the population in our observational study had a substantially shorter life expectancy. This suggests that in real life, PCTs are consulted rather late in patients' disease trajectory. Earlier involvement of PCTs may further increase their beneficial effects.

\section{Conclusion}

This observational study shows that the beneficial effects of specialist palliative care involvement are only partly occurring in the real-life clinical inpatient setting. In daily practice, PCTs are typically consulted rather late in the disease trajectory. However, our finding of significant beneficial effects even in our small group of very ill patients confirms that it is worthwhile to invest in PCT consultation in hospitalized patients. It could be desirable to use a routine structured screening instrument to ensure that all hospitalized patients with complex palliative care needs have access to specialist palliative care. Furthermore, increased involvement of a PCT and advanced care planning discussions earlier in the course of the disease, for example, at the outpatient clinic, could possibly prevent unplanned and unwanted hospitalizations in the last months of life.

\section{Acknowledgements}

We thank the patients and professionals for their participation in this study.

\section{Statement of Ethics}

The research protocol was submitted to the Medical Ethical Research Committee of Erasmus MC (MEC-2012-259), which stated that there were no objections to performing this study. Written informed consent was obtained from all patients before participating in the study.

\section{Disclosure Statement}

All authors declare that they have no conflicting interests. The study was conducted independently from the funders. All authors have full access to all data (including statistical reports and tables) in the study and take responsibility for the integrity of the data and the accuracy of the analysis. 


\section{Funding Sources}

This study was funded by ZonMw, the Netherlands Organisation for Health Research and Development (grant No. 11510031) and the Erasmus Medical Center MRACE (grant No. 2011-11112), Rotterdam, The Netherlands.

\section{Author Contributions}

A.V.H and A.B.-S. designed the study. A.B.-S. drafted the article. Y.V. gave advice regarding the statistical analysis. All authors paid significant contributions to the interpretation of the data and revised it critically for important intellectual content. All authors have approved the final manuscript.

\section{References}

1 Higginson IJ, Evans CJ. What is the evidence that palliative care teams improve outcomes for cancer patients and their families? Cancer J. 2010 Sep-Oct;16(5):423-35.

2 Parikh RB, Kirch RA, Smith TJ, Temel JS. Early specialty palliative care-translating data in oncology into practice. N Engl J Med. 2013 Dec;369(24):2347-51.

3 Kavalieratos D, Corbelli J, Zhang D, DionneOdom JN, Ernecoff NC, Hanmer J, et al. Association Between Palliative Care and Patient and Caregiver Outcomes: A Systematic Review and Meta-analysis. JAMA. 2016 Nov; 316(20):2104-14

4 Gaertner J, Siemens W, Meerpohl JJ, Antes G, Meffert C, Xander C, et al. Effect of specialist palliative care services on quality of life in adults with advanced incurable illness in hospital, hospice, or community settings: systematic review and meta-analysis. BMJ. 2017 Jul; 357:j2925.

5 Zimmermann C, Riechelmann R, Krzyzanowska M, Rodin G, Tannock I. Effectiveness of specialized palliative care: a systematic review. JAMA. 2008 Apr;299(14):1698-709.

6 Bakitas M, Lyons KD, Hegel MT, Balan S, Brokaw FC, Seville J, et al. Effects of a palliative care intervention on clinical outcomes in patients with advanced cancer: the Project ENABLE II randomized controlled trial. JAMA. 2009 Aug;302(7):741-9.

7 Temel JS, Greer JA, Muzikansky A, Gallagher ER, Admane S, Jackson VA, et al. Early palliative care for patients with metastatic nonsmall-cell lung cancer. N Engl J Med. 2010 Aug;363(8):733-42.
8 Zimmermann C, Swami N, Krzyzanowska M, Hannon B, Leighl N, Oza A, et al. Early palliative care for patients with advanced cancer: a cluster-randomised controlled trial. Lancet. 2014 May;383(9930):1721-30.

9 Higginson IJ, Finlay I, Goodwin DM, Cook AM, Hood K, Edwards AG, et al. Do hospitalbased palliative teams improve care for patients or families at the end of life? J Pain Symptom Manage. 2002 Feb;23(2):96-106.

10 Davis MP, Strasser F, Cherny N, Levan N. MASCC/ESMO/EAPC survey of palliative programs. Support Care Cancer. 2015 Jul; 23(7):1951-68.

11 Brinkman-Stoppelenburg A, Polinder S, Vergouwe Y, van der Heide A. Palliative care consultation services in hospitals in the Netherlands: the design of the COMPASS study. BMC Palliat Care. 2015 Dec;14(1):68.

12 Brinkman-Stoppelenburg A, Boddaert $M$, Douma J, van der Heide A. Palliative care in Dutch hospitals: a rapid increase in the number of expert teams, a limited number of referrals. BMC Health Serv Res. 2016 Sep;16(1): 518.

13 Dumanovsky T, Rogers M, Spragens LH, Morrison RS, Meier DE. Impact of Staffing on Access to Palliative Care in U.S. Hospitals. J Palliat Med. 2015 Dec;18(12):998-9.

14 Dutch Federation of Oncological Societies. Multidisciplinary standards for oncological care in the Netherlands-5 In. Utrecht, the Netherlands: SONCOS; 2017.

15 Moss AH, Lunney JR, Culp S, Auber M, Kurian S, Rogers J, et al. Prognostic significance of the "surprise" question in cancer patients. J Palliat Med. 2010 Jul;13(7):837-40.

16 Moroni M, Zocchi D, Bolognesi D, Abernethy A, Rondelli R, Savorani G, et al.; on behalf of the SUQ-P group. The 'surprise' question in advanced cancer patients: A prospective study among general practitioners. Palliat Med. 2014 Jul;28(7):959-64.
17 Aaronson NK, Ahmedzai S, Bergman B, Bullinger M, Cull A, Duez NJ, et al. The European Organization for Research and Treatment of Cancer QLQ-C30: a quality-of-life instrument for use in international clinical trials in oncology. J Natl Cancer Inst. 1993 Mar;85(5): 365-76.

18 Groenvold M, Petersen MA, Aaronson NK, Arraras JI, Blazeby JM, Bottomley A, et al: The development of the EORTC QLQ-C15-PAL: a shortened questionnaire for cancer patients in palliative care. Eur J Cancer. 2006 Jan; 42(1):55-64.

19 Pelayo-Alvarez M, Perez-Hoyos S, Agra-Varela Y. Reliability and concurrent validity of the Palliative Outcome Scale, the Rotterdam Symptom Checklist, and the Brief Pain Inventory. J Palliat Med. 2013 Aug;16(8):867-74.

20 Pickard AS, De Leon MC, Kohlmann T, Cella $\mathrm{D}$, Rosenbloom S. Psychometric comparison of the standard EQ-5D to a 5 level version in cancer patients. Med Care. 2007 Mar;45(3): 259-63.

21 Hearn J, Higginson IJ; Palliative Care Core Audit Project Advisory Group. Development and validation of a core outcome measure for palliative care: the palliative care outcome scale. Qual Health Care. 1999 Dec;8(4):21927.

22 EuroQol Group. EuroQol-a new facility for the measurement of health-related quality of life. Health Policy. 1990 Dec;16(3):199-208.

23 Kars MC, van Thiel GJ, van der Graaf R, Moors M, de Graeff A, van Delden JJ. A systematic review of reasons for gatekeeping in palliative care research. Palliat Med. 2016 Jun; 30(6):533-48 